\title{
Practice and Pattern of Antenatal and Postnatal Exercise among Nigerian Women: A Cross-Sectional Study
}

\author{
Chidozie Emmanuel Mbada ${ }^{1 *}$, Olubukayomi EbunOluwa Adebayo ${ }^{1}$, Taofeek Oluwole Awotidebe ${ }^{1}$, Funmilola \\ Adenike Faremi ${ }^{2}$, Monisola Omoyemi Oginni ${ }^{2}$, Abiola Oladele Ogundele ${ }^{3}$, Anne Antonette I. Emechete ${ }^{1}$
}

\begin{abstract}
Objectives: The African culture seems to play a major prohibiting role in physical exercise during pregnancy and immediate postpartum. This study was designed to assess practice and pattern of antenatal and postnatal exercise among Nigerian women. Materials and Methods: Three hundred and sixty-five women (189 pregnant women and 179 nursing mothers) from six selected hospitals in south-west Nigeria participated in this cross-sectional study. Data were obtained on socio-demographic and obstetric characteristics, and practice of antenatal and postnatal exercise. Descriptive and inferential statistics were used to analyze data at $\mathrm{P}<0.05$ alpha level.

Results: The mean age of all the respondents was $28.9 \pm 4.63$ years. A majority of the pregnant women responders were nulliparous (39.2\%) while the nursing mother responders were mostly multiparous (54.5\%). Prevalence for engagement in physical exercise was $81.9 \%$ and mostly based on self-prescription $(35.5 \%)$ and prescription by nurses $(28.8 \%)$. Antenatal and postnatal exercise practice was $84.7 \%(160 / 189)$ and $79.0 \%$ (139/176), respectively. Aerobic (43.5\%) and stretching $(33.4 \%)$ were the most common type of physical exercises. Exercise frequency was mostly 1-2 times per week (40.8\%). There was significant association between exercise practice and education level $\left(\chi^{2}=18.795 ; \mathrm{P}=0.001\right)$.

Conclusion: Engagement in antenatal and postnatal exercise among Nigerian pregnant and nursing women was high and mostly based on self-prescription. Education level significantly influence physical exercise practice among Nigerian women with aerobic and stretching as the predominant exercises in pregnancy and postpartum.

Keywords: Exercise, Nigeria, Pregnancy, Postpartum
\end{abstract}

\section{Introduction}

Exercise has become an essential aspect of antenatal and postnatal care in most settings (1-3). Pervading skepticism about safety and benefit of exercises in pregnancy and postpartum seems to be giving way to populating evidence that relevant exercise are safe and of significant benefit to the mother and child (1,3-5). Explicitly, empirical evidence revealed the benefits of exercise to include preservation and promotion of aerobic and musculoskeletal fitness levels, improvement in posture, coordination and balance, increase in endurance and stamina, deterrence of extreme maternal weight gain, gestational glucose control, improved psychological adjustment to changes in pregnancy and postpartum, facilitation of labour and more rapid postnatal recovery (4-9).

Consequent to the foregoing, the American College of Obstetricians and Gynecologists recommended low-impact, moderate-intensity and regular exercises for pregnant women irrespective of their physical fitness level for approximately 30 minutes on most days of the week.
However, there are empirical reports that women are yet to attain these recommendations $(10,11)$. Rather, there are quantity of data reporting decreased physical activity in early pregnancy (12-15), late pregnancy (14-16) and during the postpartum period (17-19). Lack of engagement in physical exercise during pregnancy and postpartum period have been implicated on a gamut of factors which may not be mutually exclusive. There is still some conservative view and myths that exercise is too delicate and unsafe for pregnant women. On the other hand, women are afraid to participate in physical exercise owing to fear that it will negatively impact on their health $(5,20)$. In addition, increase caring responsibility associated with pregnancy and postpartum and cultural perceptions are determinants of physical exercise in women. Previous investigators have reported prevalence and pattern of physical exercise among pregnant women from the developed countries (12,13,21-24). Anecdotally, the African culture seems to play a prohibiting role in physical exercises during pregnancy and immediate postpartum by man- 
dating confinement periods that varies across different tribes. However, there is an apparent dearth of such studies among African women (25). This study was designed to assess the practice and pattern of antenatal and postnatal exercise among Nigerian women.

\section{Materials and Methods}

A total of 365 (189 pregnant women and 179 nursing mothers) out of 400 women that were approached, responded in this cross-sectional study, therefore yielding a response rate of $91.3 \%$. Consecutive sampling was used to recruit respondents from six selected hospitals namely Urban Comprehensive Health Centre (UCHC), Enuwa Primary Health centre, Comprehensive Health centre Aderemi, Obafemi Awolowo University (OAU) Health Centre, OAU Teaching Hospitals Complex (OAUTHC) and Seventh Day Adventist Hospital in Ile-Ife, Osun state, south west Nigeria. Informed consent of all respondents was required for participation in the study.

A structured Knowledge, Attitude and Practice (KAP) questionnaire containing pre-coded and open questions by Walsh et al. (26) was adapted and used for data collection in this study. The content validity of the adapted version of the questionnaire was subjected to expert reviews. The reliability of the Yoruba version of the questionnaire was assessed in a pilot study by a test-retest method among 10 respondents attending the UCHC of the OAUTHC, observing 7 days between test and re-test. The summation of all the checked items on the questionnaire at test and retest were compared. The questionnaire items yielded an agreement percentage that ranged from $87.4 \%$ to $99.6 \%$, the intra-class coefficient was 0.985 and the confidence interval ranged from $0.94 \%$ to 0.996 . Respondents who were not literate in either English or Yoruba were excluded from the study. Yoruba is the local language spoken in the area where the study was conducted. This self-administered questionnaire sought information on socio-demographic, maternal infant characteristics and practice of antenatal and postnatal exercise. Respondents were asked to recall on their current antenatal or postnatal exercise pattern. Between 10 and 15 minutes was required to complete the questionnaire.

\section{Data Analysis}

Descriptive statistics of mean, standard deviation, frequency distribution were used to summarize data. Inferential statistics of Chi-square test was used to test the association between exercise practice (antenatal and postnatal) and individual factors. Alpha level was set at 0.05. Data was analyzed using SPSS version 16.0 (SPSS Inc., Chicago, USA).

\section{Results}

The mean age of all the respondents was $28.9 \pm 4.63$ years. The socio-demographic characteristics of respondents are presented in Table 1. A majority of the respondents were Christians (76.4\%), business women (39.9\%), had tertiary education (67.9\%) and were within the level of income of
$\$ 100$ to $\$ 200$ per month (29.6\%).

The maternal and obstetrics characteristics of respondents are presented in Table 2. A majority of the pregnant women responders were nulliparous (39.2\%) while the nursing mother responders were mostly multiparous (54.5\%). Spontaneous vaginal delivery was the most reported mode of delivery among the pregnant $(57.7 \%)$ and nursing (92.6\%) women, respectively. The parous respondents mostly utilized hospitals as place of delivery (68.0\%) and mostly commenced antenatal care between 3 and 6 months of pregnancy (32.1\%).

Prevalence, frequency and prescriptors of antenatal and postnatal exercise are presented in Table 3 . The total prevalence for engagement in physical exercise among the respondents was $81.9 \%$. The prevalence of antenatal and postnatal exercise practice was $84.7 \%$ and $79.0 \%$, respectively. Exercise frequency was mostly 1-2 times per week (40.8\%). Physical exercise engagement based on self-prescription $(35.5 \%)$ (i.e. engagement in exercise for therapeutic purpose without medical advice) and nurse- prescription (prescribing of exercises by nurses) by $(28.8 \%)$ were mostly reported.

The types of exercise practiced by respondents are presented in Table 4. Aerobic (43.5\%) and stretching (33.4\%) were the most common type of physical exercise practiced by the respondents. On the other hand, cycling (4.3\%) and swimming $(4.7 \%)$ were scarcely practiced among the re-

Table 1. Socio-demographic characteristics of the respondents

\begin{tabular}{|c|c|c|c|}
\hline Variable & $\begin{array}{c}\text { ANR } \\
(\mathrm{n}=189) \text { No. } \\
(\%)\end{array}$ & $\begin{array}{c}\text { PNR } \\
(n=176) \\
\text { No. }(\%)\end{array}$ & $\begin{array}{c}\text { Total } \\
(\mathrm{N}=365) \\
\text { No. (\%) }\end{array}$ \\
\hline \multicolumn{4}{|l|}{ Religion } \\
\hline Christianity & $145(76.7)$ & $134(76.1)$ & $279(76.4)$ \\
\hline Islam & $43(22.8)$ & $42(23.9)$ & $85(23.3)$ \\
\hline Traditional religion & $1(0.5)$ & $0(0)$ & $1(0.3)$ \\
\hline \multicolumn{4}{|l|}{ Occupation } \\
\hline Home maker & $23(12.2)$ & $23(13.1)$ & $46(12.6)$ \\
\hline Trading/business & $103(54.5)$ & 79 (44.9) & 184 (39.9) \\
\hline Civil servant & $39(20.6)$ & $44(25.0)$ & $83(22.7)$ \\
\hline Student & $20(10.6)$ & 21 (11.9) & $41(11.2)$ \\
\hline Not specified & $4(2.1)$ & $9(5.1)$ & $13(3.6)$ \\
\hline \multicolumn{4}{|c|}{ Educational qualification } \\
\hline Primary & $9(4.7)$ & $12(6.8)$ & $21(5.8)$ \\
\hline Secondary & 49 (25.9) & $47(26.7)$ & $96(26.3)$ \\
\hline Tertiary & $131(69.3)$ & $117(66.5)$ & $248(67.9)$ \\
\hline \multicolumn{4}{|l|}{ Family Setting } \\
\hline Polygamy & $38(20.1)$ & $46(26.1)$ & $84(23.0)$ \\
\hline Monogamy & $125(66.1)$ & $117(66.5)$ & $242(66.3)$ \\
\hline Single Parenting & $26(13.8)$ & $13(7.4)$ & $39(10.7)$ \\
\hline \multicolumn{4}{|l|}{ Income } \\
\hline Less than $\$ 100$ & 32 (16.9) & $27(15.3)$ & $59(16.2)$ \\
\hline$\$ 100-\$ 200$ & $51(27.0)$ & $57(32.4)$ & $108(29.6)$ \\
\hline$\$ 200-\$ 300$ & $38(20.1)$ & $45(25.6)$ & $83(22.7)$ \\
\hline$\$ 300-\$ 500$ & $13(6.9)$ & $15(8.5)$ & $28(7.7)$ \\
\hline$\$ 500-\$ 1000$ & $10(5.3)$ & $4(2.3)$ & $14(3.8)$ \\
\hline Greater than $\$ 1000$ & $10(5.3)$ & $5(2.8)$ & $15(4.1)$ \\
\hline Non Disclosure & $25(13.2)$ & $33(18.8)$ & $58(15.9)$ \\
\hline
\end{tabular}

ANR: Antenatal Respondents; PNR: Postnatal Respondents 
Table 2. Maternal and obstetric characteristics of the respondents

\begin{tabular}{|c|c|c|c|}
\hline Variable & $\begin{array}{l}\text { ANR }(n=189) \\
\text { No. (\%) }\end{array}$ & $\begin{array}{l}\text { PNR }(n=176) \\
\text { No. }(\%)\end{array}$ & $\begin{array}{l}\text { Total }(\mathrm{N}=365) \\
\text { No. }(\%)\end{array}$ \\
\hline \multicolumn{4}{|l|}{ Parity } \\
\hline Nulliparous & $74(39.2)$ & $0(0)$ & $74(20.3)$ \\
\hline Primiparous & $53(28.0)$ & $80(45.5)$ & $133(36.4)$ \\
\hline Multiparous & $62(32.8)$ & $96(54.5)$ & $158(43.3)$ \\
\hline \multicolumn{4}{|l|}{ Mode of delivery } \\
\hline Vaginal & $109(57.7)$ & $163(92.6)$ & $272(74.5)$ \\
\hline Caesarean Section & $6(3.2)$ & $13(7.4)$ & $19(5.2)$ \\
\hline Not Applicable & $74(39.2)$ & $0(0)$ & $74(20.3)$ \\
\hline \multicolumn{4}{|l|}{ Place of delivery } \\
\hline Hospital & 93 (49.2) & $155(88.0)$ & $248(68.0)$ \\
\hline Home & $7(3.7)$ & $5(2.8)$ & $12(3.3)$ \\
\hline Mission & 15 (7.9) & $16(9.2)$ & $31(8.5)$ \\
\hline Not applicable & $74(39.2)$ & $0(0.0)$ & $74(20.2)$ \\
\hline \multicolumn{4}{|l|}{$\begin{array}{l}\text { Previous antenatal } \\
\text { care start time }\end{array}$} \\
\hline$<1$ month & $5(2.7)$ & $25(14.2)$ & $30(8.2)$ \\
\hline $1-3$ months & $54(28.6)$ & $49(27.8)$ & $103(28.2)$ \\
\hline 3-6 months & $44(23.2)$ & $73(41.5)$ & $117(32.1)$ \\
\hline 6-9 months & $12(6.3)$ & $29(16.5)$ & $41(11.2)$ \\
\hline Not applicable & $74(39.2)$ & $0(0.0)$ & $74(20.3)$ \\
\hline \multicolumn{4}{|l|}{$\begin{array}{l}\text { Present antenatal } \\
\text { care duration }\end{array}$} \\
\hline$<1$ month & 75 (39.7) & $0(0.0)$ & $75(20.5)$ \\
\hline $1-3$ months & $57(30.2)$ & $0(0.0)$ & $57(15.6)$ \\
\hline $3-6$ months & $44(23.3)$ & $0(0.0)$ & $44(12.1)$ \\
\hline 6-9 months & $13(6.9)$ & $0(0.0)$ & $13(3.6)$ \\
\hline Not applicable & $0(0)$ & $176(100)$ & $176(48.2)$ \\
\hline
\end{tabular}

ANR: Antenatal Respondents; PNR: Postnatal Respondents

Table 3. Prevalence, frequency and prescriptors of antenatal and postnatal exercise

\begin{tabular}{|c|c|c|c|}
\hline Variable & $\begin{array}{l}\text { Antenatal No. } \\
\text { (\%) }\end{array}$ & $\begin{array}{l}\text { Postnatal } \\
\text { No. (\%) }\end{array}$ & $\begin{array}{l}\text { Total No. } \\
\text { (\%) }\end{array}$ \\
\hline Prevalence of exercise & $(n=189)$ & $(n=176)$ & $(N=365)$ \\
\hline Yes & $160(84.7)$ & $139(79.0)$ & 299 (81.9) \\
\hline No & $29(15.3)$ & $37(21.0)$ & $66(18.1)$ \\
\hline $\begin{array}{l}\text { Frequency of exercise } \\
\text { practice/week }\end{array}$ & $(n=160)$ & $(n=139)$ & $(n=299)$ \\
\hline $1-2$ times & $65(40.6)$ & $57(41.0)$ & $122(40.8)$ \\
\hline 3-4 times & $49(30.6)$ & $52(37.4)$ & $101(33.8)$ \\
\hline$>4$ times & $46(28.8)$ & $30(21.6)$ & $76(25.4)$ \\
\hline \multicolumn{4}{|l|}{ Prescriptor of exercise } \\
\hline \multicolumn{4}{|l|}{ Doctor } \\
\hline Yes & $26(16.3)$ & $23(16.5)$ & $49(16.4)$ \\
\hline No & $134(83.7)$ & $116(83.5)$ & $250(83.6)$ \\
\hline \multicolumn{4}{|l|}{ Nurse } \\
\hline Yes & $45(28.1)$ & $41(29.5)$ & $86(28.8)$ \\
\hline No & 115 (71.9) & $98(70.5)$ & $213(71.2)$ \\
\hline \multicolumn{4}{|l|}{ Physical therapist } \\
\hline Yes & $56(35.0)$ & $27(19.4)$ & $83(27.8)$ \\
\hline No & $104(65.0)$ & $112(80.6)$ & $216(72.2)$ \\
\hline \multicolumn{4}{|l|}{ Spouse } \\
\hline Yes & $7(4.4)$ & $10(7.2)$ & $17(5.7)$ \\
\hline No & $153(95.6)$ & $129(92.8)$ & $282(94.3)$ \\
\hline \multicolumn{4}{|l|}{ Self } \\
\hline Yes & $52(32.5)$ & $54(38.8)$ & $106(35.5)$ \\
\hline No & $108(67.5)$ & $85(61.2)$ & $193(64.5)$ \\
\hline
\end{tabular}

Table 4. Types of antenatal and postnatal exercise practiced by respondents $(n=299)$

\begin{tabular}{|c|c|c|c|}
\hline Variable & $\begin{array}{c}\text { ANR }(n=160) \\
\text { No. (\%) }\end{array}$ & $\begin{array}{c}\text { PNR ( } n=139) \\
\text { No. (\%) }\end{array}$ & $\begin{array}{c}\text { Total }(\mathrm{N}=299) \\
\text { No. (\%) }\end{array}$ \\
\hline \multicolumn{4}{|l|}{ Aerobics } \\
\hline Yes & $65(40.6)$ & $65(46.8)$ & $130(43.5)$ \\
\hline No & $95(59.4)$ & $74(53.2)$ & $169(56.5)$ \\
\hline \multicolumn{4}{|c|}{ Abdominal exercise } \\
\hline Yes & $40(25.0)$ & $23(16.5)$ & $63(21.1)$ \\
\hline No & $120(75.0)$ & $116(83.5)$ & 236(78.9) \\
\hline \multicolumn{4}{|c|}{ Pelvic floor exercise } \\
\hline Yes & $22(13.7)$ & $33(23.7)$ & $55(18.4)$ \\
\hline No & $138(86.3)$ & $106(76.3)$ & $244(81.6)$ \\
\hline \multicolumn{4}{|c|}{ Back care exercise } \\
\hline Yes & $28(17.5)$ & $20(12.5)$ & $48(16.1)$ \\
\hline No & $132(82.5)$ & $119(87.5)$ & 251(83.9) \\
\hline \multicolumn{4}{|c|}{ Swimming } \\
\hline Yes & $8(5.0)$ & $6(4.3)$ & $14(4.7)$ \\
\hline No & $152(95.0)$ & 133(95.7) & 285(95.3) \\
\hline \multicolumn{4}{|l|}{ Cycling } \\
\hline Yes & $5(3.1)$ & $8(5.8)$ & $13(4.3)$ \\
\hline No & 155(96.9) & $131(94.2)$ & 286(95.7) \\
\hline \multicolumn{4}{|c|}{ Stretching exercise } \\
\hline Yes & $57(35.6)$ & $43(30.9)$ & $100(33.4)$ \\
\hline No & $103(64.4)$ & $96(69.1)$ & 199(66.6) \\
\hline \multicolumn{4}{|c|}{$\begin{array}{l}\text { Relaxation and } \\
\text { breathing exercise }\end{array}$} \\
\hline Yes & $42(26.3)$ & $30(21.6)$ & $72(24.1)$ \\
\hline No & $118(73.7)$ & 109(78.4) & $227(75.9)$ \\
\hline \multicolumn{4}{|c|}{$\begin{array}{l}\text { Muscle strengthening } \\
\text { exercise }\end{array}$} \\
\hline Yes & $36(22.5)$ & $40(28.8)$ & $76(25.4)$ \\
\hline No & $124(77.5)$ & $99(71.2)$ & $223(74.6)$ \\
\hline
\end{tabular}

ANR: Antenatal Respondents; PNR: Postnatal Respondents

spondents.

Chi-square test of association between exercise practice and socio-demographic and obstetric characteristics is presented in Table 5. The result showed a significant direct association between exercise and education level $\left(\chi^{2}=18.795 ; \mathrm{P}=0.001\right)$ with respondents with tertiary education level reporting higher exercise practice (72.9\%).

\section{Discussion}

This study assessed practice and pattern of antenatal and postnatal exercise among Nigerian women. The study found a high prevalence of engagement in physical exercise among Nigerian pregnant and nursing women. However, comparison of this study's finding is limited by apparent dearth of data on level of engagement in exercise among Nigerian pregnant and nursing women over time. Nonetheless, this finding may be an indication of a paradigm shift in attitude towards exercise in pregnancy and postpartum period. Anecdotal observation in the study environment is in agreement with previous submissions that acceptance of modern antenatal care, engagement in exercise and delivery care among pregnant women from Africa is inhibited by cultural myths, traditional beliefs and misperceptions (27-30).

Many cultures in Africa, based on fatalistic views observe 
Table 5. Chi-square test of association between exercise practice and socio-demographic and obstetric characteristics

\begin{tabular}{|c|c|c|c|c|}
\hline \multirow[t]{2}{*}{ Variable } & \multicolumn{2}{|c|}{ Exercise practice } & \multirow{2}{*}{$\chi^{2}$} & \multirow{2}{*}{ P-value } \\
\hline & Yes, Number (\%) & No, Number (\%) & & \\
\hline Age group & & & 1.577 & 0.209 \\
\hline$<30$ years & 179 (59.9) & $45(68.2$ & & \\
\hline$\geq 30$ years & $120(40.1)$ & $21(31.8)$ & & \\
\hline Education & & & 18.795 & 0.001 \\
\hline Primary & $15(5)$ & $6(9.1)$ & & \\
\hline Secondary & $66(22.1)$ & $30(45.5)$ & & \\
\hline Tertiary & 218 (72.9) & $30(45.4)$ & & \\
\hline Occupation & & & 9.134 & 0.058 \\
\hline Home maker & $37(12.4)$ & $9(13.6)$ & & \\
\hline Trading/business & $148(49.5)$ & $34(51.5)$ & & \\
\hline Civil servant & $74(24.7)$ & $9(13.6)$ & & \\
\hline Student & $28(9.4)$ & $13(19.7)$ & & \\
\hline Not specified & $12(4)$ & $1(1.5)$ & & \\
\hline Parity & & & 0.157 & 0.925 \\
\hline Nulliparous & $61(20.4)$ & $13(19.7)$ & & \\
\hline Primiparous & $110(36.8)$ & $23(34.8)$ & & \\
\hline Multiparous & $128(42.8)$ & $30(45.5)$ & & \\
\hline
\end{tabular}

* Significance at $\alpha=0.05$

taboos during pregnancy and postpartum. However, socio-economic conditions seem to have diminished the practice of seclusion and confinement during pregnancy. Nonetheless, during postpartum, confinement periods up to 40 days or more are still enforced by mother inlaw and elderly women in the community to protect the mother and infant from disease and evil spirit. During the confinement periods, mothers are often put on long bed rest and feeding on certain diets in order to restore the contraction of the uterus, dry the womb, reduce postpartum haemorrhage, establish milk production and healing of the perineum or caesarean section incision. However, these mothers are restrained from physical activity and exercises based on beliefs that exercises are contra-indicated and alter the formation of new blood. In contrast, empirical finding from this study revealed high physical exercise practice rate among the women. However, the finding on prevalence of engagement in physical exercise among women in this study should be treated with caution because the respondents in study comprised of women attending antenatal or postnatal clinics who may have imbibed health promotion and education on importance of exercises as component of antenatal and postnatal care. It is therefore advocated that a community-based survey may be needed to validate the finding of this hospital-based survey.

This study found that most of the women engaged in physical exercise based on self-prescription. Self-prescription of exercise in pregnancy and postpartum portend a negative dimension to a positive development. Self-prescription of exercise in pregnancy and postpartum may be associated with the availability of wide range of information emanating from family, friends, print materials, internet and the social media. Most of this information is confusing, unscientific and lacking in specificity. On the other hand, self-prescription of exercise in pregnancy and post- partum may be as a result of non-availability of competent and qualified exercise experts such as a women's health or obstetric physical therapist. Furthermore, the result of this study showed that more women engaged in physical exercise based on prescription by nurses than physical therapists. This finding confirms the non-availability of specialist physical therapists in most of the selected hospitals where this study was conducted. Nurses and midwives have been reported as the commonest information sources on exercise in pregnancy and postpartum in other studies $(31,32)$. Specifically, Whitford et al. (33) in a study in north-east Scotland, found that midwives were the health professionals most likely to give information on pelvic floor exercises. Although, physicians, nurses, midwives and community health aides often prescribe exercises in some settings, may not possess the requisite knowledge of the principles, prescription, indications and contraindications to exercise in pregnancy and postpartum. Competent supervision is significant for maintaining quality of exercise. Studies have shown that physical therapists' supervised exercise in pregnancy and postpartum resulted in improved outcomes (33-35). However, healthcare professionals prescribing exercise in pregnancy and postpartum should seek knowledge of the potential risks and basic tenets of exercise prescription in health and disease. This study found aerobic and stretching as the predominant physical exercise types in pregnancy and postpartum. This study corroborates previous findings that have found aerobic and stretching exercises as simple, easy to do and adequate in pregnancy (4,36-39). Although, cycling and swimming have quantity of support in literature as ideal exercises in pregnancy and postpartum, they were scarcely practiced among the women in this study. Swimming is far remote as a way of life of the people in the study environment and there is lack of swimming skills and limited availability of swimming pools. This is further complicat- 
ed by prevalent hydrophobia and superstitions that make swimming a taboo for pregnant and nursing women. Furthermore, non-availability or non-affordability of bicycle ergometer for exercise may have contributed to low rate of cycling exercise among the women in this study.

Lastly, this study found significant association between exercise practice and education level. Women with higher level of education were more involved in exercise in pregnancy and postpartum. This finding is consistent with some previous reports that have associated higher participation in physical activity or exercise with higher education $(12,14,24,40,41)$. Petersen et al. (42) in a study on correlates of physical activity among pregnant women in the United States found that pregnant women meeting the moderate or vigorous physical activity recommendations were more likely to be younger, non-Hispanic white, more educated, not married, nonsmokers, and to have higher incomes. Gaston and Cramp (43) in a review on exercise in pregnancy found higher education and income as predictors of higher exercise participation during pregnancy. The psychometric properties of the original instrument from which the questionnaire in this study was adapted was not reported by the authors. Therefore, lack of information on validity and reliability of the original instrument and the use of the same questionnaire for a heterogeneous sample is a potential limitation of this present study. However, the findings of this study were presented under the pregnant and nursing women dichotomy and thus reduce possible influence of homogeneity of sample.

\section{Conclusion}

Nigerian pregnant and nursing women demonstrate high engagement in physical exercises which were usually by self-prescription. Higher education is a significant determinant of exercise participation during pregnancy among Nigerian women. The predominant exercise types in pregnancy and postpartum were aerobic and stretching.

\section{Ethical issues}

Ethical approval for the study (IPHOAU/12/13) was obtained from the Health Research Ethics Committee of the Institute of Public Health, OAU, Ile-Ife, Nigeria.

\section{Financial support}

No grant was received to conduct this study. However, the ACU Early Career Travel Grant was received towards dissemination of the findings of this study.

\section{Conflict of interests}

Authors declare no conflict of interests.

\section{Acknowledgments}

The authors gratefully acknowledge all respondents, and the administrative and nursing staff of the different hospitals selected for this survey. The Early Careers Grants offered by Association of Commonwealth Universities (ACU) towards the presentation of part of the findings of this study is immensely appreciated.

\section{References}

1. ACOG Committee Obstetric Practice. ACOG Committee opinion. Number 267, January 2002: exercise during pregnancy and the postpartum period. Obstet Gynecol 2002; 99(1):171-3.

2. Davies GA, Wolfe LA, Mottola MF, MacKinnon C, Arsenault MY, Bartellas E, et al. Exercise in pregnancy and the postpartum period. J Obstet Gynaecol Can 2003;25(6):516-29.

3. Wadsworth P. The benefits of exercise in pregnancy. J Nurse Practitioners 2007;3(5):333-9.

4. Artal R, O'Toole M. Guidelines of the American College of Obstetricians and Gynecologists for exercise during pregnancy and the postpartum period. Br J Sports Med 2003;37(1):6-12.

5. Shelby S. Medical report: Exercise in the postpartum period. ACSM'S Health Fitness J 2006;10(4):40-1.

6. Artal R, Platt LD, Sperling M, Kammula RK, Jilek J, Nakamura R. Maternal cardiovascular and metabolic responses in normal pregnancy. Am J Obstet Gynecol 1981;140(2):123-7.

7. Clapp JF III. Exercise in pregnancy: a brief clinical review. Fetal Med Rev 1990;161:1464-9.

8. Lokey EA, Tran ZV, Wells CL, Myers BC, Tran AC. Effects of physical exercise on pregnancy outcomes: a meta-analytic review. Med Sci Sports Exerc 1991;23(11):1234-9.

9. Sternfeld B, Quesenberry CP Jr, Eskenazi B, Newman LA. Exercise during pregnancy and pregnancy outcome. Med Sci Sports Exerc 1995;27(5):634-40.

10. Soultanakis HN, Artal R, Wiswell RA. Prolonged exercise in pregnancy: glucose homeostasis, ventilatory and cardiovascular responses. Semin Perinatol 1996;20(4):315-27.

11. Artal R, Sherman C. Exercise during pregnancy. Safe and beneficial for most. Phys Sportsmed 1999; 27(8):560. doi: 10.3810/psm.1999.08.947.

12. Evenson KR, Savitz DA, Huston SL. Lesure-time physical activity among pregnant women in the US. Paediatr Perinat Epidemiol 2004;18(6):400-7.

13. Pivarnik JM, Chambliss HO, Clapp JF, Dugan SA, Hatch MC, Lovelady CA, et al. Impact of physical activity during pregnancy and postpartum on chronic disease risk. Med Sci Sports Exerc 2006;38(5):989-1006.

14. Mottola MF, Campbell MK. Activity patterns during pregnancy. Can J Appl Physiol 2003;28(4):642-53.

15. Pereira MA, Rifas-Shiman SL, Kleinman KP, RichEdwards JW, Peterson KE, Gillman MW. Predictors of change in physical activity during and after pregnancy. Am J Prev Med 2007;32(4):312-9.

16. Borodulin KM, Evenson KR, Wen F, Herring AH, Benson AM. Physical activity patterns during pregnancy. Med Sci Sports Exerc 2008;40(11):1901-8. doi: 10.1249/MSS.0b013e31817f1957.

17. Fell DB, Joseph KS, Armson BA, Dodds L. The impact of pregnancy on physical activity level. Maternal Child Health J 2009;13(5):597-603. doi: 10.1007/s10995-0080404-7.

18. Schmidt MD, Pekow P, Freedson PS, Markenson G, Chasan-Taber L. Physical activity patterns during 
pregnancy in a diverse population of women. J Women Health 2006;15(8):909-18.

19. van Raaij JM1, Schonk CM, Vermaat-Miedema SH, Peek ME, Hautvast JG. Energy cost of physical activity throughout pregnancy and the first year postpartum in Dutch women with sedentary lifestyles. Am J Clin Nutr 1990;52(2):234-9.

20. Blum JW, Beaudoin CM, Caton-Lemos L. Physical activity patterns and maternal well-being in postpartum women. Matern Child Health J 2004; 8(3):163-9.

21. Treuth MS, Butte NF, Puyau M. Pregnancy-related changes in physical activity, fitness, and strength. Med Sci Sports Exerc 2005;37(5):832-7.

22. Women and Physical Activity [database on the Internet]. 2010 [cited 24/01/2014]. Available from: http://www.whv.org.au

23. Hegaard HK, Damm P, Hedegaard M, Henriksen TB, Ottesen B, Dykes AK, et al. Sports and leisure time physical activity during pregnancy in nulliparous women. Matern Child Health J 2011;15(6):806-13. doi: 10.1007/s10995-010-0647-y.

24. Domingues MR, Barros AJ. Leisure-time physical activity during pregnancy in the 2004 Pelotas Birth Cohort Study. Rev Saude Publica 2007;41(2):173-80.

25. Liu J, Blair SN, Teng Y, Ness AR, Lawlor DA, Riddoch C. Physical activity during pregnancy in a prospective cohort of British women: results from the Avon longitudinal study of parents and children. Eur J Epidemiol 2011;26(3):237-47. doi: 10.1007/s10654010-9538-1.

26. Walsh JM, McGowan C, Byrne J, McAuliffe FM. Prevalence of physical activity among healthy pregnant women in Ireland. Int J Gynaecol Obstet 2011;114(2):154-5. doi: 10.1016/j.ijgo.2011.02.016.

27. Adeniyi AF, Ogwumike OO, Bamikefa TR. Postpartum exercise among Nigerian women: Issues relating to exercise performance and self-efficacy. ISRN Obstet Gynecol 2013;2013:294518. doi: 10.1155/2013/294518

28. Ribeiro CP, Milanez H. Knowledge, attitude and practice of women in Campinas, São Paulo, Brazil with respect to physical exercise in pregnancy: a descriptive study. Reprod Health 2011;8:31. doi: 10.1186/1742-4755-8-31.

29. Logan C. Traditional beliefs and practices of pregnancy and childbirth. Botsw Natl Health Bull 1985;1(1):64-75.

30. Krans EE, Chang JC. Low-income African American women's beliefs regarding exercise during pregnancy. Matern Child Health J 2012;16:1180-7.

31. Igberase GO. Harmful cultural practices and reproductive health in Nigeria. Continental J Tropic Med 2012;6(1):27-33.

32. Omobola OC. An overview of taboo and superstition among the Yoruba of Southwest of Nigeria. Mediterranean Journal of Social Sciences 2013;4(2):221-6.

33. Whitford HM, Alder B, Jones M. A cross-sectional study of knowledge and practice of pelvic floor exercises during pregnancy and associated symptoms of stress urinary incontinence in North-East Scotland. Midwifery 2006;23(2):204-17.

34. Hermansen IL, O'Connell BO, Gaskin CJ. Women's explanations for urinary Incontinence, their management strategies, and their quality of life during the postpartum period. J Wound Ostomy Continence Nurs 2010;37(2):187-92. doi: 10.1097/ WON.0b013e3181cf7946.

35. Abdulaziz K, Hasan T. Role of pelvic floor muscle therapy in obese perimenopausal females with stress incontinence: A randomized control trial. Internet J Radiology 2012;14 (2). Available from: https://ispub. com/IJRA/14/2/14430

36. Robledo-Colonia AF, Sandoval-Restrepo N, Mosquera-Valderrama YF, Escobar-Hurtado C, Ramírez-Vélez R. Aerobic exercise training during pregnancy reduces depressive symptoms in nulliparous women: a randomised trial. J Physiother 2012;58(1):9-15. doi: 10.1016/S18369553(12)70067-X.

37. Kasawara KT, Burgos CS, do Nascimento SL, Ferreira NO, Surita FG, Pinto E Silva JL. Maternal and perinatal outcomes of exercise in pregnant women with chronic hypertension and/or previous preeclampsia: A randomized controlled trial. ISRN Obstet Gynecol 2013;2013:857047. doi: 10.1155/2013/857047.

38. Wolfe LA, Hall P, Webb KA, Goodman L, Monga M, McGrath MJ. Prescription of aerobic exercise during pregnancy. Sports Med 1989;8(5):273-301.

39. Koltyn KF, Schultes SS. Psychological effects of an aerobic exercise session and a rest session following pregnancy. J of Sports Med Phys Fitness 1997;37(4):287-91.

40. Larson-Meyer DE. Effect of postpartum exercise on mothers and their offspring: a review of the literature. Obes Res 2002;10(8):841-53.

41. Davies GA, Wolfe LA, Mottola MF, MacKinnon C, Society of Obstetricians and gynecologists of Canada, SOGC Clinical Practice Obstetrics Committee. Joint SOGC/CSEP clinical practice guideline: exercise in pregnancy and the postpartum period. Can J Appl Physiol 2003;28(3):330-41.

42. Petersen AM, Leet TL, Brownson RC. Correlates of physical activity among pregnant women in the United States. Med Sci Sports Exerc 2005;37(10):1748-53.

43. Gaston A, Cramp A. Exercise during pregnancy. A review of patterns and determinants. J Sci Med Sport 2011;14(4):299-305.

Copyright $\odot 2015$ The Author(s); This is an open-access article distributed under the terms of the Creative Commons Attribution License (http://creativecommons.org/licenses/by/4.0), which permits unrestricted use, distribution, and reproduction in any medium, provided the original work is properly cited. 